\title{
Effect of HEBP (1-Hydroxyethylidene-1,1- Bisphosphonate) on Experimental Osteoporosis Induced by Ovariectomy in Rats
}

\author{
Akifumi Togari, Michitsugu Arai, Masatoshi Hironaka, \\ Shosei Matsumoto and Hisashi Shinoda ${ }^{1}$ \\ Department of Pharmacology, School of Dentistry, Aichi-Gakuin University, \\ 1-100 Kusumoto-cho, Chikusa-ku, Nagoya 464, Japan \\ 'Department of Pharmacology. School of Dentistry, Tohoku University. \\ 4-1 Seiryo-cho, Aoba-ku, Sendai 980, Japan
}

Received November 5, 1990 Accepted March 22, 1991

\begin{abstract}
The present study was undertaken to test whether long term administration of HEBP could prevent the progress of bone loss induced by ovariectomy in rats. Administration of HEBP was started from day 111 after ovariectomy. The animals received subcutaneous injections of HEBP, at a dose of $0,2,4$, or $8 \mathrm{mg} / \mathrm{kg}$, every other day for 92 days. Tibiae, femora and incisor teeth were investigated by chemical analyses and by contact microradiography. Effects on calcium, phosphorus, and alkaline phosphatase activity in the plasma were also examined. Progress in the loss of bone density and ash content caused by ovariectomy was prevented by the administration of $2 \mathrm{mg} / \mathrm{kg}$ HEBP for 92 days and was partially prevented by the administration of $4 \mathrm{mg} / \mathrm{kg}$. At a dose of $8 \mathrm{mg} / \mathrm{kg}$, however, HEBP did not prevent the bone loss but, rather, potentiated it. These chemical findings were qualitatively confirmed by contact microradiography. A dose-dependent inhibition was observed in the mineralization of incisor dentin. These results suggest that HEBP, at least at low dose levels in which the inhibition of mineralization is not predominant, has a potency to prevent the progress of bone loss induced by ovariectomy. At higher doses, however, this compound seems not to be effective, because of the severe inhibition of mineralization.
\end{abstract}

1-Hydroxyethylidene-1,1-bisphosphonate (HEBP) has been used for the treatment of various pathological conditions characterized by increased bone destruction such as Paget's disease $(1-6)$, tumoral bone destruction, and hypercalcemia of malignancy $(7,8)$. The therapeutic usefulness of HEBP in these diseases has been indicated by various experimental studies. In growing rats, HEBP blocks the resorption of bone and cartilage so that the metaphysis becomes radiologically more dense than normal $(9-11) .{ }^{45} \mathrm{Ca}$ kinetic studies (12) as well as studies of ${ }^{45} \mathrm{Ca}$ release from cultured calvaria (13) have shown that this compound inhibits bone resorption in a dosedependent fashion. HEBP also reduces bone resorption which has been induced by various other means. Thus, HEBP blunts the effect of parathyroid hormone (14) and inhibits tumoral invasion of bone, various types of tumoral hypercalcemia and periodontal destruction (15-18).

However, many studies have shown that HEBP at higher doses not only inhibits bone 
resorption but also retards the mineralization of normal calcified tissues and causes accumulation of unmineralized osteoid tissues in bone and cartilage $(9-11,19,20)$. HEBP has also been reported to inhibit the mineralization of dentin which does not remodel (21, 22).

The fact that HEBP inhibits both bone resorption and mincralization raises the question of whether this compound could cause an actual increase in bone mass and whether it can be used against osteoporosis. So far, HEBP has been tested on a number of experimental osteoporosis models; In low doses, HEBP prevented bone loss induced by immobilization $(23-28)$, by heparin (29), and by a low calcium diet (28). In human studies, a series of so called coherence therapies have been performed by cyclic short period dosing of an activator of bone resorption before or together with HEBP $(30-33)$. Although the results are still controversial, it appcars that the administration of HEBP can lead to an increase in bone mass.

The present study was undertaken to test whether long term administration of HEBP could prevent the progress of bone loss induced by ovariectomy in rats. We also examined the effect of HEBP on the mineralization of dentin in order to estimate the effectiveness of the compound on bone mineralization in the ovaricctomized rat.

\section{MATERIALS AND METHODS}

Forty-four female Sprague-Dawley rats, aged 6 weeks, were purchased from Shizuoka Animal Center (Hamamatsu, Japan). One week later, 14 rats were given a sham operation (OVE $(-)$ control rats) and 30 rats werc ovariectomized under ether ancsthesia. To establish bone loss in ovariectomized rats, all the animals were maintained for 110 days under regulated $12 \mathrm{hr} / 12 \mathrm{hr}$ light-dark illumination cycles at a constant temperature (23 $\left.\pm 1^{\circ} \mathrm{C}\right)$ and humidity $(50 \pm 10 \%)$. During the course of the experiment, they were fed standard laboratory chow (CE-2, Nihon Crea Co.
Ltd., Tokyo) containing $1.16 \%$ calcium and $0.98 \%$ phosphorus, ad libitum. On day 110 after the surgical operations, 7 sham-operated rats and 6 ovariectomized rats were killed by bleeding from the abdominal aorta and served as the pre-treatment controls. On day 111 , the remaining 24 ovariectomized rats were divided into 4 groups, and administration of HEBP was started. Each group of 6 rats was injected subcutaneously with HEBP (Sumitomo Pharmaceutical Co., Ltd., Osaka, Japan) at a dose of either $0(\mathrm{OVE}(+)$ control rats), 2, 4 , or 8 $\mathrm{mg} / \mathrm{kg}$ every other day for 92 days. For the OVE $(+)$ control rats, $0.9 \% \mathrm{NaCl}$ solution was injected. The rats were weighed at appropriate times during the course of the experiment. At the end of the experiment, plasma was collected from the abdominal aorta under light ether anesthesia. After killing the animal by bleeding, tibiae, femora, maxillae, and mandibulae were dissected from each animal and then stored in $10 \%$ formalin saturated with magnesium carbonate.

Plasma calcium and phosphorus concentrations were determined using an atomic absorption spectrophotometer (Type 180-60, Hitachi, Tokyo) and the method of Chen et al. (34), respectively. For the determination of calcium, plasma was diluted with lanthanum- $\mathrm{HCl}$ to eliminate phosphorus interference in the sample. Alkaline phosphatase activity in the plasma was determined by the previously described method (35).

After dissecting femora from adhering soft tissues, their volumes were measured by the method described by Saville (36). The femora were then defatted with chloroform/ethanol (1: 1) solution, dried in an oven at $110^{\circ} \mathrm{C}$ for $12 \mathrm{hr}$, and then ashed in a muffle furnace at $900^{\circ} \mathrm{C}$ for $6 \mathrm{hr}$. Maxillary incisors were dissected from the maxillac, and then they were dried, weighed, and ashed in the same way as were the femora. The ash was dissolved in $1 \mathrm{~N}$ $\mathrm{HCl}$, and calcium and phosphorus concentrations were determined in the same way as in plasma.

Tibiae and mandibulae were dehydrated by means of a graded series of ethanol solutions, 
and then they were embedded in polyester resin (Ligorac, Nissin EM Inc., Tokyo). Frontal sections of proximal tibia and transverse sections of incisor dentin at the first molar region of mandibulae, all with a thickness of $50 \mu \mathrm{m}$, were prepared using a thin sectioning machine (Type CT-1, Kosaka Laboratory, Ltd, Tokyo), followed by manual grinding with whetstones and abrasive papers. Contact microradiographs of the ground sections were taken using a soft X-ray apparatus (Sofron, Koken Co., Ltd., Tokyo).

Statistical differences between the treatment groups were estimated by Duncan's test.

\section{RESULTS}

\section{Body weight (Fig. 1)}

Increases in the body weight in $\operatorname{OVE}(+)$

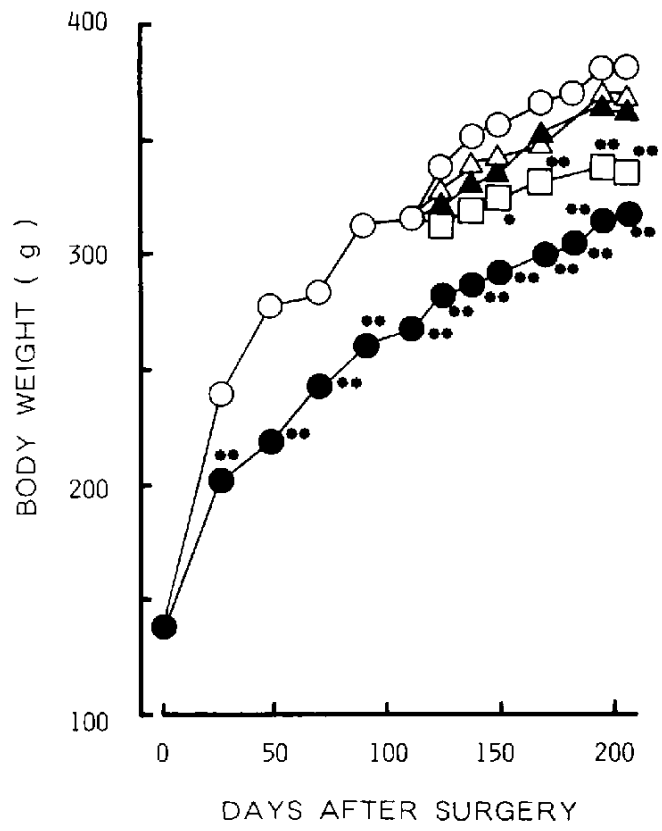

Fig. 1. Changes in body weight in rats. Rats were sham-operated (O) or ovariectomized $(O)$ on day 0 . From day 111 following ovariectomy, HEBP at doses of $2(\Delta), 4$ ( $\Delta$ ), or $8 \mathrm{mg} / \mathrm{kg}(\square)$ was injected subcutaneously every other day for 92 days. Each point represents the mean value $(n=6-7) . * P<0.05$, ${ }^{* *} \mathrm{P}<0.01$, statistical difference from the ovariectomized control group at corresponding times. control rats were significantly higher than those in $\operatorname{OVE}(-)$ control rats. On day 202, the mean body weights \pm S.E.M. in OVE $(-)$ control rats and $\operatorname{OVE}(+)$ control rats were $317 \pm 10(n=7)$ and $382 \pm 8 \mathrm{~g}(\mathrm{n}=6)$, respectively. The increase in body weight caused by the ovariectomy was prevented by the administration of HEBP at a dose of $8 \mathrm{mg} / \mathrm{kg}$. At doses of 2 and $4 \mathrm{mg} / \mathrm{kg}$, this compound did not have any statistically significant effects on the body weight.

Calcium, phosphorus, and alkaline phosphatase activity in the plasma (Table 1)

The effects on calcium, phosphorus, and alkaline phosphatase activity in the plasma are shown in Table 1. Neither ovariectomy nor administration of HEBP had any significant effect on biochemical parameters in the plasma.

Mineral content in femur and incisor (Tables 1 and 2)

Ovariectomy induced a marked decrease in the ash content of the femur 110 days after the surgical operation. The mean ash weights per unit bone volume $(\mathrm{A} / \mathrm{V})$ in $\mathrm{OVE}(+)$ control rats was $94.0 \%$ of that in $\mathrm{OVE}(-)$ control rats on day 110 and decreased to about $92 \%$ on day 202 (Tables 1 and 2).

The administration of $2 \mathrm{mg} / \mathrm{kg}$ HEBP reversed the decreased ash content to the same level as that in the $\mathrm{OVE}(-)$ control rats on day 202. At the dose of $4 \mathrm{mg} / \mathrm{kg}$, the mean value for ash content was still higher than that in the OVE $(+)$ control rats, but the difference was not statistically significant. At the dose of $8 \mathrm{mg} / \mathrm{kg}$, the ash content of the femur was almost the same as that in $\operatorname{OVE}(+)$ control rats.

Both calcium and phosphorus content per unit dry weight of femur were decreased by the administration of HEBP for 92 days at doses of 4 and $8 \mathrm{mg} / \mathrm{kg}$, as compared with those in the OVE (-) control rats. The decreases in phosphorus were larger than those in calcium. The effects of HEBP on the ash, calcium, and phosphorus content of the maxil- 
Table 1. Biochemical parameters in plasma, characteristics in femoral bone, and characteristics in incisor teeth in sham operated rats and in ovariectomized rats treated with or without HEBP on day 202

\begin{tabular}{|c|c|c|c|c|c|}
\hline & \multirow{2}{*}{$\begin{array}{l}\text { Sham operated rats } \\
\text { (OVE }(-) \text { control) }\end{array}$} & \multicolumn{4}{|c|}{ Dose $(\mathrm{mg} / \mathrm{kg})$ of HEBP in ovariectomized rats } \\
\hline & & $0(\mathrm{OVE}(+)$ control $)$ & 2 & 4 & 8 \\
\hline \multicolumn{6}{|l|}{ Plasma } \\
\hline Calcium (mg/dl) & $10.6 \pm 0.29$ & $10.4 \pm 0.54$ & $10.4 \pm 0.37$ & $10.1 \pm 0.59$ & $10.0 \pm 0.45$ \\
\hline Phosphorus (mg/dl) & $5.0 \pm 0.63$ & $5.4 \pm 0.59$ & $5.5 \pm 0.30$ & $5.0 \pm 0.71$ & $5.2 \pm 0.59$ \\
\hline $\begin{array}{l}\text { ALP activity } \\
(\mathrm{nmol} / \mathrm{min} / \mathrm{ml})\end{array}$ & $78.4 \pm 38.9$ & $104.4 \pm 35.0$ & $124.3 \pm 17.7$ & $96.1 \pm 30.9$ & $77.0 \pm 14.2$ \\
\hline \multicolumn{6}{|l|}{ Femur } \\
\hline Ash/volume (\%) & $68.3 \pm 1.87$ & $62.8 \pm 3.41^{++}$ & $68.5 \pm 1.21^{* *}$ & $65.4 \pm 1.36$ & $61.9 \pm 4.66^{\dagger \dagger}$ \\
\hline $\mathrm{Ca} /$ dry weight (\%) & $22.2 \pm 0.60$ & $21.8 \pm 0.48$ & $21.9 \pm 0.54$ & $21.3 \pm 0.56^{\dagger}$ & $21.2 \pm 0.87^{\dagger}$ \\
\hline $\mathrm{P} /$ dry weight $(\%)$ & $10.5 \pm 0.23$ & $10.5 \pm 0.27$ & $10.5 \pm 0.41$ & $9.8 \pm 0.23^{+* * *}$ & $9.7 \pm 0.32^{\dagger+* *}$ \\
\hline $\mathrm{Ca} / \mathrm{P}$ ratio & $2.12 \pm 0.04$ & $2.09 \pm 0.05$ & $2.09 \pm 0.04$ & $2.15 \pm 0.02^{*}$ & $2.19 \pm 0.04^{\dagger+* *}$ \\
\hline \multicolumn{6}{|l|}{ Incisor } \\
\hline Ash/dry weight (\%) & $74.0 \pm 0.64$ & $74.0 \pm 0.59$ & $74.3 \pm 0.60$ & $72.9 \pm 1.05$ & $69.3+3.61^{++* *}$ \\
\hline $\mathrm{Ca} /$ dry weight $(\%)$ & $26.9 \pm 0.53$ & $27.7 \pm 0.66$ & $27.5 \pm 0.78$ & $27.4 \pm 0.83$ & $27.0 \pm 0.99$ \\
\hline $\mathrm{P} /$ dry weight $(\%)$ & $13.1 \pm 0.29$ & $14.7 \pm 0.48^{+\dagger}$ & $14.3 \pm 0.25^{\dagger \dagger}$ & $13.8 \pm 0.45^{+* *}$ & $11.3 \pm 0.67^{\dagger+* *}$ \\
\hline $\mathrm{Ca} / \mathrm{P}$ ratio & $2.05 \pm 0.06$ & $1.90 \pm 0.05^{\dagger}$ & $1.88 \pm 0.17^{\dagger}$ & $1.99 \pm 0.04$ & $2.39 \pm 0.13^{\dagger+* *}$ \\
\hline
\end{tabular}

Each value represents the mean \pm S.D. $(\mathrm{N}=6-7){ }^{+}: \mathrm{P}<0.05,{ }^{+}: \mathrm{P}<0.01$, statistical difference from the OVE $(-)$ control rats by Duncan's test. ${ }^{*}: \mathrm{P}<0.05,{ }^{*}: \mathrm{P}<0.01$, statistical difference from the $\mathrm{OVE}(+)$ control rats by Duncan's test.

Table 2. Characteristics of femoral bone in sham operated rats and in ovariectomized rats on day 110

\begin{tabular}{lcc}
\hline & $\begin{array}{c}\text { Sham-operated } \\
\text { rats (OVE }(-))\end{array}$ & $\begin{array}{c}\text { Ovariectomized } \\
\text { rats (OVE }(+))\end{array}$ \\
\hline Ash/volume (\%) & $71.7 \pm 2.33$ & $67.4 \pm 2.62^{*}$ \\
$\mathrm{Ca} /$ dry weight $(\%)$ & $24.1 \pm 0.45$ & $22.7 \pm 0.86^{*}$ \\
$\mathrm{P} /$ dry weight $(\%)$ & $11.7 \pm 0.21$ & $10.9 \pm 0.17^{*}$ \\
$\mathrm{Ca} / \mathrm{P}$ ratio & $2.08 \pm 0.01$ & $2.08 \pm 0.07$ \\
\hline
\end{tabular}

Each value represents the mean \pm S.D. $(\mathrm{N}=6-7)$.

${ }^{*}: \mathrm{P}<0.01$, Statistical difference by Duncan's test.

lary incisors are shown in Table 1 . The ash content per unit dry weight was decreased by the administration of HEBP at the dose of 8 $\mathrm{mg} / \mathrm{kg}$ as compared with the content in $\operatorname{OVE}(-)$ or $\mathrm{OVE}(+)$ control rats. Neither ovariectomy nor the administration of HEBP had any significant effect on the calcium content of the incisor. As to the phosphorus content, however, ovariectomy induced a signifcant increase, and administration of HEBP at the dose of $8 \mathrm{mg} / \mathrm{kg}$ induced a significant decrease in the mean value.

\section{Contact microradiography (Figs. 2 and 3)}

Contact microradiographs of proximal tibiae on day 110 after the ovariectomy are shown in Fig. 2. Decrease in bone density in the proximal tibiae, caused by ovariectomy, were already observed before HEBP administration; the density of cancellous bone in the epiphysis and that of trabecular bone in the metaphysis were much less than those in the OVE (-) control rats. Contact microradiographs of proximal tibiae on day 202 after the ovariectomy are shown in Fig. 3A. Further decreases in the bone density of the proximal tibiae were observed. However, the decreased bone density was reversed to the normal level of OVE $(-)$ control rats by the administration of $2 \mathrm{mg} / \mathrm{kg}$ HEBP (Fig. 3A, c). At a dose of 4 $\mathrm{mg} / \mathrm{kg}$, bone densities in the epiphysis and metaphysis were still higher than those in OVE $(t)$ control rats (Fig. 3A, d). At the dose of $8 \mathrm{mg} / \mathrm{kg}$, a series of transverse lines with low mineral density appeared in the metaphysis, and a widening of unmineralized growth cartilage due to the inhibition of endochondral ossification was observed. In addition, cylindrical-shaped metaphyses, which was 

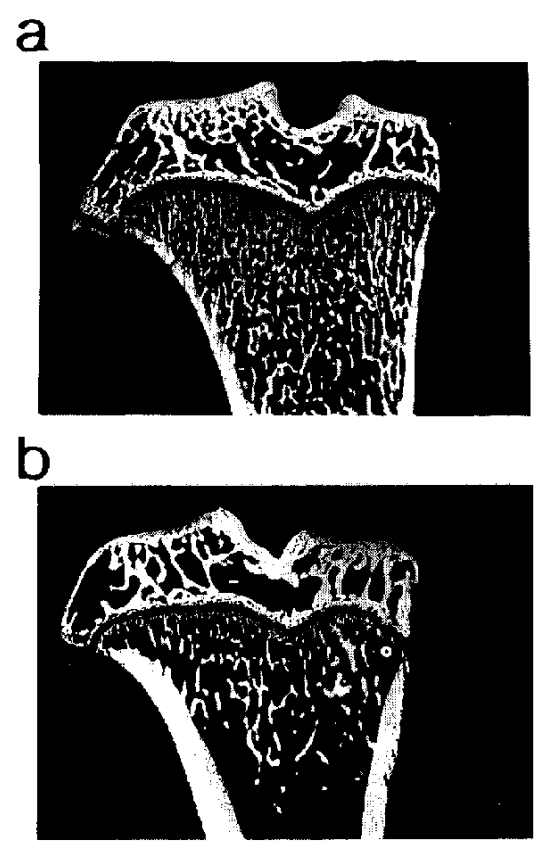

Fig. 2. Contact microradiographs of the proximal tibia 110 days after sham-operation (a) or ovariectomy (b).

caused by the inhibition of resorption at the periosteal surfaces in the metaphysis, were observed. An accumulation of osteoid tissue was also observed in the metaphysis.

Contact microradiographs of dentin transverse sections are shown in Fig. 3B. Ovariectomy appeared not to have any effect on the dentin formation (Fig. 3B, a and b). HEBP, on the other hand, caused a dose-dependent inhibition of mineralization in the incisor dentin (Fig. 3B, c, d and e); At a dose of 2 $\mathrm{mg} / \mathrm{kg}$, a series of slightly radiolucent layers appeared in the dentin. The contact microradiographs showed the presence of regularly spaced alternating layers of low and high radiolucency which surrounded the dental pulp in a concentric fashion. At the dose of 4 $\mathrm{mg} / \mathrm{kg}$, the radiolucency of each hypomineralized layer increased. It seems that each layer of low mineral density corresponds to inhibition of mineralization after each injection of HEBP and is followed by a recovery period.
At the dose of $8 \mathrm{mg} / \mathrm{kg}$, not only severe hypomineralized layers, but also marked partial arrest of dentin accretion, which led to an irregular contour of the dentin, were observed in all of the specimens examined.

\section{DISCUSSION}

In the present study, we examined the chronic effect of HEBP on the formation of bone and incisor dentin in ovariectomized rats which is known to be a useful experimental model of osteoporosis $(37-42)$. Ovariectomy caused a decrease in the trabecular bone mass in the tibia and the ash content in femur. It also caused an increase in body weight which is one of the prominent features of ovariectomy and has been posturated to provide partial protection against the development of osteopenia in the long bones (41). In this study, a high dose of HEBP $(8 \mathrm{mg} / \mathrm{kg})$, but not lower doses, prevented the body weight increase normally observed after ovariectomy. The reason why this prevention occurred is not known, since HEBP has been reported to have lower subacute and chronic toxicity. The main significant side effects reported so far are the inhibition of mineralization of the skeleton as shown in this study and an increase in plasma phosphate in humans $(3,43)$. The latter effect, however, has not been found in any other animal species including rats. It is probable that the prevention of the increase in the body weight after the high dose of HEBP might, at least partially, be due to the inhibition of mineralization in the skeletal tissues which must lead to a decrease in the total weight of skeletal tissues in the body.

In the present study, we demonstrated that bone loss after ovariectomy was prevented by the administration of HEBP at a low dose. This result was consistent with Shiota's previous observation that $0.5 \mathrm{mg} / \mathrm{kg} /$ day of HEBP counteracted the bone loss caused by ovariectomy (28). There are some differences between Shiota's experiment and ours in terms of the timing and the length of HEBP administration; Shiota started HEBP treatment just 
A
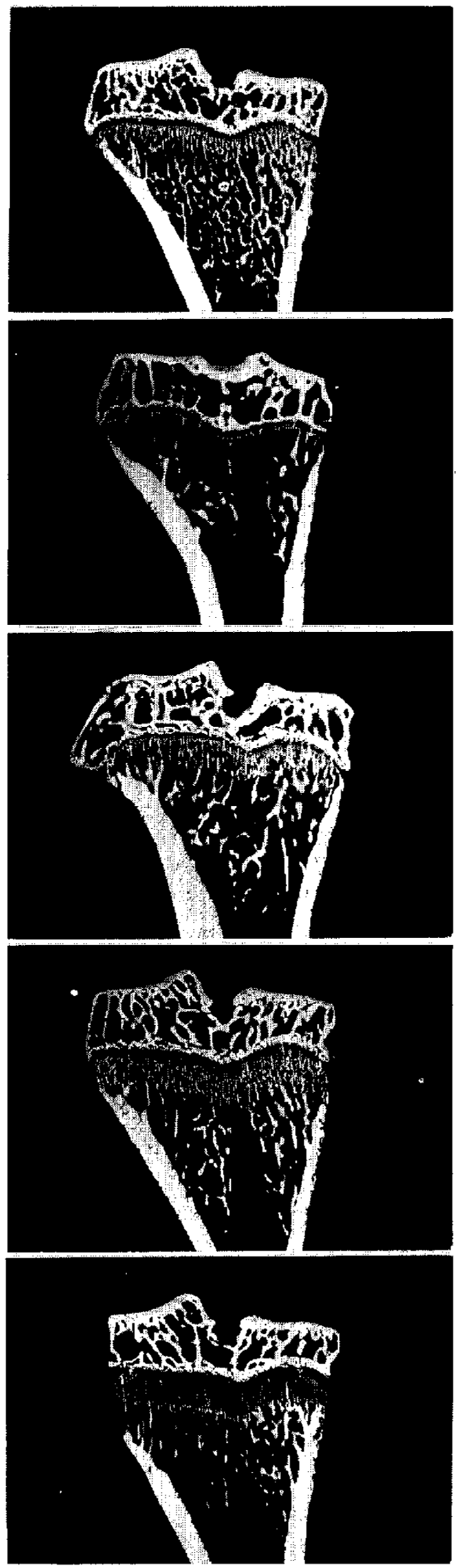

B

a
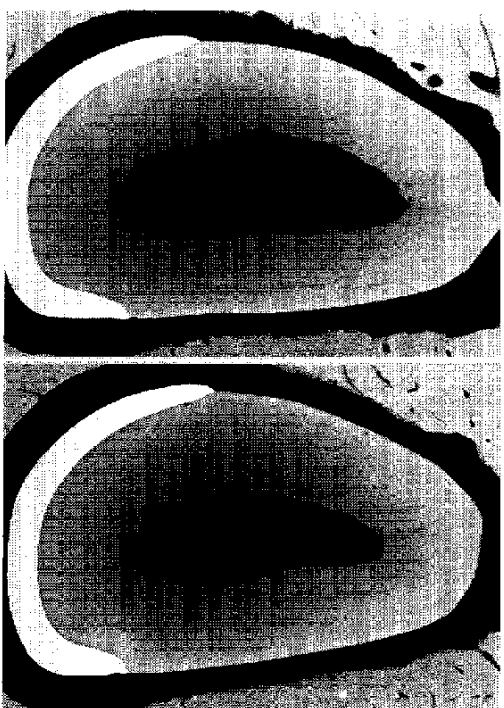

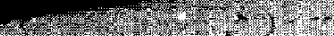

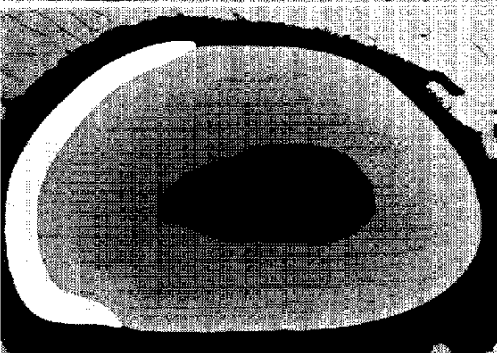

C

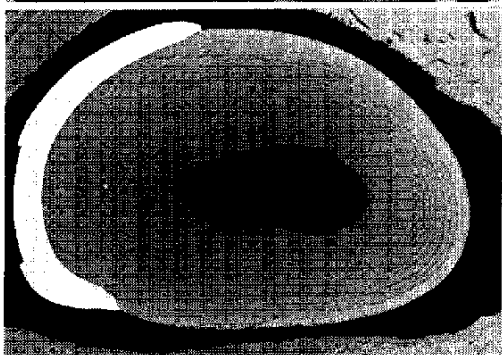

d

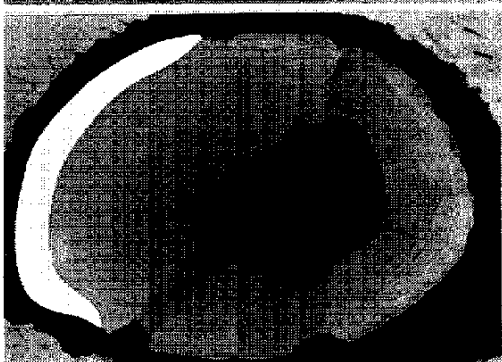

Fig. 3. Contact microradiographs of the proximal tibia (A) and dentin (B) from sham-operated (a) and ovariectomized rats treated with HEBP at at dosc of 0 (b), 2 (c), 4 (d), or $8 \mathrm{mg} / \mathrm{kg}$ (c). 
after the ovariectomy and continued the treatment every day for 6 months, while we started the treatment 110 days after the ovariectomy, when the bone loss had already developed, and we continued the treatment every other day for 3 months. Since the total dose of HEBP given in Shiota's experiment was nearly the same as in our experiment using $2 \mathrm{mg} / \mathrm{kg}$ of HEBP (Shiota's data: $0.5 \mathrm{mg} / \mathrm{kg}$ $\times 6$ months, present data: $2.0 \mathrm{mg} / \mathrm{kg} \times 3$ months/2), we can conclude that HEBP has the potency not only to counteract bone loss, but also to prevent the progress of bone loss induced by ovariectomy.

HEBP at higher doses, however, did not prevent the bone loss, but rather potentiated it. The contradictory effect of HEBP on bone density might be explained as follows: HEBP inhibits both bone resorption and mineralization in a dose-dependent fashion (9-12). However, it has been shown that the dose response curves for these processes are not parallel, especially in higher doses. Gasser et al. (12) reported that with high doses of $\mathrm{HEBP}$, when the mineralization of bone and cartilage matrix was impaired, calcium balance became less positive, because bone mineralization fell more than bone resorption and a decrease in bone mineral ensued. This might be a pertinent explanation of the results observed with 8 $\mathrm{mg} / \mathrm{kg}$ of HEBP in the present study. At this dose, severe inhibition of mineralization was observed in the growth cartilage and in incisor dentin. A substantial amount of ostcoid accumulation was also observed in the tibial metaphysis.

The hypomineralization caused by higher doses of HEBP was accompanied by a decrease of phosphorus in the bone and in the incisor teeth of the ovariectomized rats. This suggests that the mineral deposited into bone and teeth following high doses of HEBP was not of the usual quality and had a higher $\mathrm{Ca} / \mathrm{P}$ ratic than normal. Francis (44) and Francis et al. (45) have shown that bisphosphonates have effects very similar to those of pyrophosphate on the behavior of calcium salts in vitro. Thus, bisphosphonates inhibit the precipitation of calcium phosphate from solution and block the transformation of amorphous calcium phosphate into hydroxyapatite. If HEBP in vivo also blocked the phase transformation of calcium phosphate crystals into stable hydroxyapatite, a decrease in minerals with lower $\mathrm{Ca} / \mathrm{P}$ ratios might result, since calcium phosphates such as brushite and octacalcium phosphate have lower $\mathrm{Ca} / \mathrm{P}$ ratios than hydroxyapatite. However, this seemed not to be the case. The mechanism underlying the decrease in the phosphorus content of the bone and teeth remains to be elucidated.

In the present study, incisor dentin was examined to assess the effect of HEBP on the mineralization. The advantage to using dentin was that the drug effect on the mineralization can be separated from the effect on bone resorption, since no resorbing process is involved in the dentin formation in contrast to bone. Thus, in the present study, the inhibitory effect of HEBP on the mineralization could be readily detected in the dentin even at a low dose $(2 \mathrm{mg} / \mathrm{kg})$. In contrast, the effect on mineralization was not evident in the bone tissues, although it became evident as the dose of HEBP became higher. In this sense, incisor dentin could be expected as a simple and useful material for evaluating drug effects on mineralization.

In summary, the present study demonstrated that long term administration of HEBP at low doses is fairly effective for preventing the progress of bone loss induced by ovariectomy. However, if excessive doses are administered, inhibition of mineralization, as has previously been described $(9-12)$, might result.

\section{Acknowledgment}

HEBP was kindly supplied by Sumitomo Pharmaceutical Co., Ltd.

\section{REFERENCES}

1 Smith, R., Russell, R.G.G. and Bishop, M. Diphosphonates and Paget's disease of bone. Lancet 1, 945-947 (1971)

2 Altman, R.D., Johnston, C.C., Khairi, M.R.A., 
Wellman, H., Serafini, A.N. and Sankey, R.R.: Influcnce of disodium ctidronate on clinical and laboratory manifestations of Paget's disease of bone (osteitis deformans). N. Engl. J. Med. 289, $1379-1384$ (1973)

3 Russell, R.G.G., Smith, R., Preston, C., Walton, R.J. and Woods, C.G.: Diphosphonates in Paget's disease. Lancet 1, 894-898 (1974)

4 Fleisch, H.: Experimental basis for the clinical use of diphosphonates in Paget's disease of bone. Arthritis Rheum. 23, 1162-1171 (1980)

5 Johnston, C.C., Jr., Khairi, M.R.A. and Meunier, P.J.: Use of etidronate (EHDP) in Paget's disease of bone. Arthritis Rhcum. 23, $1172-1176$ (1980)

6 Alexandre, C.M., Chapuy, M.C., Vignon, E., Edouard, C., Eng, B.S., Johnston, C.C. and Meunier, P.J.: Treatment of Paget's disease of bone with ethanc-1-hydroxy-1,1 diphosphonate (EHDP) at a low dosage $(5 \mathrm{mg} / \mathrm{kg} /$ day). Clin. Orthop. 174, 193-205 (1983)

7 Jung, A.: Comparison of two parenteral diphosphonates in hypercalcemia of malignancy. Am. J. Med. 72, 221-226 (1982)

8 Ryzen, E., Martodam, R.R., Troxell, M., Benson, A., Paterson, A., Shepard, K. and Hicks, R.: Intravenous etidronate in the management of malignant hypercalcemia. Arch. Intern. Med. 145, $449-$ 452 (1985)

9 Schenk, R., Merz, W.A., Mühlbauer, R., Russell, R.G.G. and Fleisch, H.: Effect of ethane-1hydroxy-1,1-diphosphonate (EHDP) and dichloromethylene diphosphonate $\left(\mathrm{Cl}_{2} \mathrm{MDP}\right)$ on the calcification and resorption of cartilage and bone in the tibial epiphysis and metaphysis of rats. Calcif. Tissue Res. 11, 196- 214 (1973)

10 Miller, S.C. and Jee, W.S.S.: Ethane-1-hydroxy1,1-diphosphonate (EHDP). Effects on growth and modeling of the rat tibia. Calcif. Tissue Res. 18, 215-231 (1975)

11 Miller, S.C. and Jee, W.S.S.: The comparative effects of dichloromethylene diphosphonate $\left(\mathrm{Cl}_{2}\right.$ MDP) and cthane-1-hydroxy-1,1-diphosphonate (EHDP) on growth and modeling of the rat tibia. Calcif. Tissue Res. 23, $207-214$ (1977)

12 Gasser, A.B., Morgan, D.B, Fleisch, H. and Richelle, L.J.: The influence of two diphosphonates on calcium metabolism in rat. Clin. Sci. 43, 31 - 45 (1972)

13 Reynolds, J.J., Murphy, H., Mühlbauer, R.C., Morgan, D.B. and Fleisch, H.: Inhibition by diphosphonates of bone resorption in mice and comparison with grey-lethal osteopetrosis. Calcif. Tissue Res. 12, 59-71 (1973)

14 Russell, R.G.G., Mühlbauer, R.C., Bisaz, S., Wil- liams, D.A. and Fleisch, H.: The influence of pyrophosphate, condensed phosphates, phosphonates and other phosphate compounds on the dissolution of hydroxyapatite in vitro and on bonc resorption induced by parathyroid hormone in tissue culture and in thyroparathyroidectomized rats. Calcif. Tissue Res. 6, 183-196 (1970)

15 Leonard, E.P., Resse, W.V. and Mandel, E.J.: Comparison of the effects of ethane-1-hydroxy-1,1diphosphonate and dichloromethylene diphosphonate upon periodontal bone resorption in rice rats (oryzomys palustris). Arch. Oral Biol. 24, 707708 (1979)

16 Johnson, K.Y., Wesseler, M.A., Olsen, H.M., Martodam, R.R. and Poser, J.W.: The effects of diphosphonates on tumor-induced hypercalcemia and osteolysis in Walker carcinosarcoma 256 (W256) of rats. In Diphosphonates and Bone, Edited by Donath, A. and Courvoisier, B., p. 386-394, Editions Médecine et Hygiène, Gèneve (1982)

17 Jung, A., Bornand, J., Mermillod, B., Edouard, C. and Meunier, P.J.: Inhibition by diphosphonates of bone resorption induced by the Walker tumor of the rat. Cancer Res. 44, 3007-3011 (1984)

18 Kobayashi, M., Noguchi, T., Kinoshita, S. and Shinoda, H.: Inhibitory effects of EHDP (ethanc1-hydroxy-1,1-diphosphonate) on the resorption of alveolar bone in rats. Japan. J. Oral Biol. 26, $629-639$ (1984)

19 Jowsey, J., Holley, K.E. and Linman, J.W.: Effect of sodium etidronate in adult cats. J. Lab. Clin. Med. 76, 126-133 (1970)

20 King, W.R., Francis, M.D. and Michael, W.R.: Effect of disodium ethane-1-hydroxy-1,1-diphosphonate on bone formation. Clin. Orthop. 78, $251-270(1971)$

21 Larsson, A. and Larsson, S.E.: Studies on dentinogenesis in the rat. Ethane-1-hydroxy-1,1-diphosphonate (EHDP) inhibits crystal growth in predentin calcification. Virchows Arch. [A] 360, 315-325 (1973)

22 Larsson, $\stackrel{\AA}{\text {.: }}$ The short-term effects of high doses of ethylene-1-hydroxy-1,1-diphosphonate upon carly dentin formation. Calcif. Tissue Res. 16, 109127 (1974)

23 Fleisch, H., Russell, R.G.G., Simpson, B. and Mühlbauer, R.C.: Prevention by a diphosphonate of immobilization osteoporosis in rats. Nature 223, $211-212$ (1969)

24 Cabanela, M.E. and Jowsey, J.: The effects of phosphonates on experimental osteoporosis. Calcif. Tissue Res. 8, 114-120 (1971)

25 Michael, W.R., King, W.R. and Francis, M.D.: 
Effectiveness of diphosphonates in preventing osteoporosis of disuse in the rat. Clin. Orthop. 78, $271-276$ (1971)

26 Mühlbauer, R.C., Russell, R.G.G., Williams, D.A. and Fleisch, H.: The effects of diphosphonates, polyphosphates, and calcitonin on immobilisation osteoporosis in rats. Eur. J. Clin. Invest. 1, 336-344 (1971)

27 Lane, J.M. and Steinberg, M.E.: The role of diphosphonates in osteoporosis of disuse. J. Trauma 13, 863-869 (1973)

28 Shiota, E.: Effects of diphosphonate on osteoporosis induced in rats. Rocntogenological, histological and biomechanical studies. Fukuoka Acta Med. 76, 317-342 (1985)

29 Hähnel, H., Mühlbach, R., Lindenhayn, K., Schaetz, P, and Schmidt, U.J.: Zum Enfluss von Diphosphonat auf die experimentelle Heparinosteopathie. Z. Alternforsch. 27, $289-292$ (1973)

30 Anderson, C., Cape, R.D.T., Crilly, R.G., Hodsman, A.B. and Wolfe, B.M.J.: Preliminary observations of a form of coherence therapy for osteoporosis. Calcif. Tissue Int. 36, $341-343$ (1984)

31 Hesch, R.D., Heck, J., Delling, G., Keck, E., Reeve, J., Canzler, H., Schober, O., Harms, H. and Rittinghaus, E.F.: Results of a stimulatory therapy of low bone metabolism in osteoporosis with ( I-38)hPTH and diphosphonate EHDP. Protocol of study I, osteoporosis trial hannover. Klin. Wochenschr. 66, 976-984 (1988)

32 Hodsman, A.B.: Effects of cyclical therapy for osteoporosis using an oral regimen of inorganic phosphate and sodium etidronate: a clinical and bone histomorphometric study. Bone Miner. 5, $201-212$ (1989)

33 Watts, N., Harris, S.T., Genant, H., Wasnich, R., Miller, P., Jackson, R., Licata, A., Ross, P., Woodson, G.C., Yanover, M.J., Mysiw, W.J., Kohse, L., Rao, M.B., Steiger, P., Richmond, B. and Chesunt, C.H.: Intermittent cyclical etidronate treatment of postmenopausal osteoporosis. N. Engl. J. Med. 323, $73-79$ (1990)

34 Chen, P.S., Toribara, T.Y. and Warner, H.: Microdetermination of phosphorus. Analyt. Chem. 28, $1756-1758(1956)$
35 Togari, A., Sakai, J., Matsumoto, S. and Nagatsu, T.: Highly sensitive assay for alkaline and acid phosphatase activities by high-performance liquid chromatography with electrochemical detection. J. Chromatogr. 417, $41-46$ (1987)

36 Saville, P.D.: Changes in skeletal mass and fragility with castration in the rat: a model of osteoporosis. J. Am. Geriatr. Soc. 17, $155-166$ (1969)

37 Orimo, H., Fujita, T. and Yoshikawa, M.: Increased sensitivity of bone to parathyroid hormone in ovaricctomized rats. Endocrinology 90, 760763 (1972)

38 Wronski, T.J., Lowry, P.L., Walsh, C.C. and Ignaszewski, L.A.: Skeletal alterations in ovariectomized rats. Calcif. Tissue Int. 37, 324-328 (1985)

39 Turner, R.T., Vandersteenhoven, J.J. and Bell, N.H.: The effects of ovariectomy and $17 \beta$-estradiol on cortical bone histomorphometry in growing rats. J. Bone Miner. Res. 2, 115-122 (1987)

40 Turner, R.T., Wakley, G.K., Hannon, K.S. and Bell, N.H.: Tamoxifen prevents the skeletal effects of ovarian hormone deficiency in rats. J. Bone Miner. Res. 2, 449 - 456 (1987)

41 Wronski, T.J., Schenck, P.A., Cintrón, M. and Walsh, C.C.: Effect of body weight on osteopenia in ovariectomized rats. Calcif. Tissue Int. 40, 155159 (1987)

42 Wronski, T.J., Cintrón, M. and Dann, L.M.: Temporal relationship between bone loss and increased bone turnover in ovariectomized rats. Calcif. Tissue Int. 43, 179-183 (1988)

43 Guncăga, J., Lauffenburger, Th., Lentner, C., Dambacher, M.A., Haas, H.G., Fleisch, H. and Olah, A.J.: Diphosphonate treatment of Paget's disease of bone. A correlated metabolic, calcium kinetic and morphometric study. Horm. Metab. Res. 6, 62-69 (1974)

44 Francis, M.D.: The inhibition of calcium hydroxyapatite crystal growth by polyphosphonates and polyphosphates. Calcif. Tissue Res. 3, 151-162 (1969)

45 Francis, M.D., Russell, R.G.G. and Fleisch, H.: Diphosphonates inhibit formation of calcium phosphate crystals in vitro and pathological calcification in vivo. Science 165, 1264 - 1266 (1969) 